\title{
Investigation on the Vibration Effect of Shock Wave in Rock Burst by In Situ Microseismic Monitoring
}

\author{
Mingshi Gao, ${ }^{1,2}$ Hongchao Zhao $\mathbb{D},{ }^{1,3}$ Yichao Zhao, ${ }^{2}$ Xiaojun Gao, ${ }^{2}$ and Xiangyu Wang ${ }^{2}$ \\ ${ }^{1}$ School of Geology and Mining Engineering, Xinjiang University, Urumqi, Xinjiang 830046, China \\ ${ }^{2}$ School of Mines, Key Laboratory of Deep Coal Resource Mining, China University of Mining and Technology, Xuzhou, \\ Jiangsu 221116, China \\ ${ }^{3}$ School of Civil, Mining and Environmental Engineering, University of Wollongong, Northfield, NSW 2500, Australia
}

Correspondence should be addressed to Hongchao Zhao; xjuzhc@163.com

Received 20 September 2017; Accepted 4 January 2018; Published 26 March 2018

Academic Editor: Salvatore Russo

Copyright (C) 2018 Mingshi Gao et al. This is an open access article distributed under the Creative Commons Attribution License, which permits unrestricted use, distribution, and reproduction in any medium, provided the original work is properly cited.

Rock burst is a physical explosion associated with enormous damage at a short time. Due to the complicity of mechanics of rock burst in coal mine roadway, the direct use of traditional investigation method applied in tunnel is inappropriate since the components of surrounding rock are much more complex in underground than that of tunnel. In addition, the reliability of the results obtained through these methods (i.e., physical simulation, theoretical analysis, and monitoring in filed application) is still not certain with complex geological conditions. Against this background, present experimental study was first ever conducted at initial site to evaluate the effect of shock wave during the rock burst. TDS-6 microseismic monitoring system was set up in situ to evaluate the propagation of shock wave resulting in microexplosions of roadway surrounding rock. Various parameters including the distance of epicentre and the characteristic of response have been investigated. Detailed test results revealed that (1) the shock wave attenuated exponentially with the increase of the distance to seismic source according to the equation of $E=E_{0} e^{-\eta l}$; particularly, the amplitude decreased significantly after being $20 \mathrm{~m}$ apart from explosive resource and then became very weak after being $30 \mathrm{~m}$ apart from the seismic source; (2) the response mechanics are characteristic with large scatter based on the real location of surrounding rock despite being at the same section. That is, the surrounding rock of floor experienced serious damage, followed by ribs, the roof, and the humeral angles. This in situ experimental study also demonstrated that microseismic monitoring system can be effectively used in rock burst through careful setup and data investigation. The proposed in situ monitoring method has provided a new way to predict rock burst due to its simple instalment procedure associated with direct and reasonable experimental results.

\section{Introduction}

During the past decades, approximately $85 \%$ of rock burst happened in roadways resulting in series fatal accidents characteristic with cave-ins, collapse, and even instantaneous closure of roadways [1-4]. Enormous damage in terms of the claims of miners and equipment damage occurred at the same time due to the closure of roadway which is regarded as a throat of underground mine caused by rock burst [5]. Particularly, in recent years, China's coal mining operators have experienced gradual transformation into a predominantly deep mining. Rock burst is therefore becoming a main concern due to its high frequency and seriousness owing to the increase of in situ stress in terms of the mining depth $[6,7]$. Correspondingly, the stability of surrounding rocks in roadway subjected to rock burst draws more and more attentions than ever before. Many investigations have been conducted into the generation and behaviour mechanisms of rock burst in tunnel and, as a result, a number of theoretical assumptions have been proposed. However, different to other mechanical phenome, it is nearly impossible to rebuild the real occurrence of rock burst in the laboratory resulting in the uncertain of its generation mechanisms and failure mode of surrounding rock. These research methods can be classified in three categories: (a) physical simulation study with similar material, (b) theoretical analysis thorough finite element 
simulation, and (c) monitoring in field application [6, 8-10]. In the first category, the physical simulation is mainly carried out by means of drilling the hole to simulate the tunnel after the balance of the model, followed by the artificial explosive near the tunnel. For this physical simulation method, the experimental results mainly depend on the selection of similar materials and the source of explosive. However, the main concern for this method is its reasonability and accuracy owing to the simplification of the surrounding rock to be homogenous in simulation even though the results are more direct. In addition, the scale of physical simulation model is another restriction of its wide use, because that it is well known that the transformation of explosive wave is relevant to the scale of the model. Last but not least, it is difficult to monitor on-time value with traditional equipment in laboratory. Therefore, physical simulation should be a qualitative method to evaluate the possible failure mode of tunnel at initial stage. In the second category, the rock burst is investigated using theoretical analysis depending on various soft programmes. Compared to physical simulation, the boundary restriction is not still a main problem with large calculation ability of soft program. Moreover, much more parameters including cracks and faults can be added to surrounding rock subjected to rock burst so that the results are mostly approached to real application. However, proper selection of key parameters is still on the way of developing to improve the accuracy of simulation since it is impossible to rebuild the real surrounding rock due to not only the complex of rock but also the limitation of calculation ability of normal computer. Accordingly, it is still a new approach to most engineer in site application to acquire theoretical analysis. For monitoring technology applied in field application, the result is obviously clear and direct; however, it is not a costeffective method for research due to its long-term monitoring and large number to be analysed [11-16]. In particular, some critical parameters affecting the accuracy are still uncertain since it is impossible to rebuild the rock burst in real mine. Most importantly, these three categories are mostly in terms of tunnelling rather than mining engineering. In early studies of roadway rock burst in underground mines, two typical research methods mentioned were directly used in analysis. Subsequent studies, however, have shown that this direct use is inappropriate since the components of surrounding rock are much complex in underground compared to that of tunnelling. Although a large amount of existing research revealed that the relationship between shock wave and rock burst can be used to predict the occurrence of rock burst [17-21], these results are inconsistent with regard to in situ behaviour. This is also because the stress distribution of surrounding rock is mainly influenced by other mining activities. Correspondingly, the cost-effective and reliable method to investigate the behavior of rock burst is required.

Against this background, the first author of this paper therefore proposed a new in situ approach to investigate the behaviour of rock burst in coal mine roadway with the use of microseismic monitoring system (MMS). Compared to physical simulation in laboratory, both the boundary and scale of the model are real without any coefficient; the results of this experimental approach are much more direct and reliable.
Different from FE analysis which relays on professional staff, this proposed method can be carried out by ordinal mining engineers. In addition, the use of portable monitoring system reduces the cost and the number of engineers compared with traditional monitoring technology in field application. To clarify the above expected advantages, an in situ case study was firstly conducted in 2604 working panel of Xinqiao coal mine in China by using TDS- 6 microseismic monitoring system (MMS) to develop a deep understanding of the relationship between shake wave and microexploration and the response characteristics. The propagation of shock wave stimulated by microexplosion and response characteristics of the surrounding rock in the measurement of the effects arising therefrom are investigated through in situ assessment.

\section{Geology and in Site Situation}

All tests were conducted at the tail gate of 2604 working panel of Xinqiao coal mine located at Henan province, China (Figure 1). Ground elevation of the roadway is $31.8 \mathrm{~m}$ and the caving depth ranges from $-361 \mathrm{~m}$ to $-512 \mathrm{~m}$. 2604 working panel was excavated along the top of \#2-II coal seam. The \#2II coal seam is relatively stable with slope gradient of $10^{\circ} \sim 15^{\circ}$. Moreover, the change of thickness is not very obvious, that is, ranging from $1.57 \mathrm{~m}$ to $2.57 \mathrm{~m}$ with an average of $2.07 \mathrm{~m}$. Coal reject consisted of dark coal, mirror coal, and glass luster which has been found in coal seam. The combined geological column of coal seam is shown in Figure 2.

The tailgate is under an anticlinal structure where there is decrease in both ribs. The inclination of the coal seam along is $10^{\circ} \sim 15^{\circ}$, with an average of $13^{\circ}$. It is expected that the excavation procedure of 2604 working panel may be affected by DF23 fault resulting in the observation of significant cracks on surrounding rock of roadway.

The width and height of the tailgate is about $3400 \mathrm{~mm}$ and $2100 \mathrm{~mm}$, respectively. The primary support is the combination of anchor (bolt) and cable. The diameter and length of the high-strength bolt installed on the roof of tailgate are $\Phi 20 \mathrm{~mm}$ and $2000 \mathrm{~mm}$. All high-strength bolts spacing 800 $\times 800 \mathrm{~mm}$ with the force of $80 \mathrm{KN}$ and preload of $150 \mathrm{~N} \cdot \mathrm{m}$ are fixed with two rolls of MSK2335 resin. In addition, $3600 \mathrm{~mm}$ W-type steel bars (No.BHW-220-2.75) and steel mesh with grid of $50 \times 50 \mathrm{~mm}$ have been used together with bolts. Moreover, $\Phi 18.9 \mathrm{~mm} \times 6300 \mathrm{~mm}$ anchor spacing $3000 \mathrm{~mm}$ is installed as secondary support. All anchors were preloaded with $100 \mathrm{kN}$. Other details information about support can be found from Figures 3 and 4.

\section{TDS-6 Microseismic Monitoring System}

3.1. TDS-6 MMS System. TDS-6 microseismic monitoring system, jointly developed by China University of Mining \& Technology and the State Seismological Bureau, was used in this case study. The system consists of six data acquisition branch stations and one data collection master station as shown in Figure 5.

The master station is equipped with a data receiver unit and a data recorder. Recorded files, waveforms, and seismic events can be replayed, recorded, and located through 


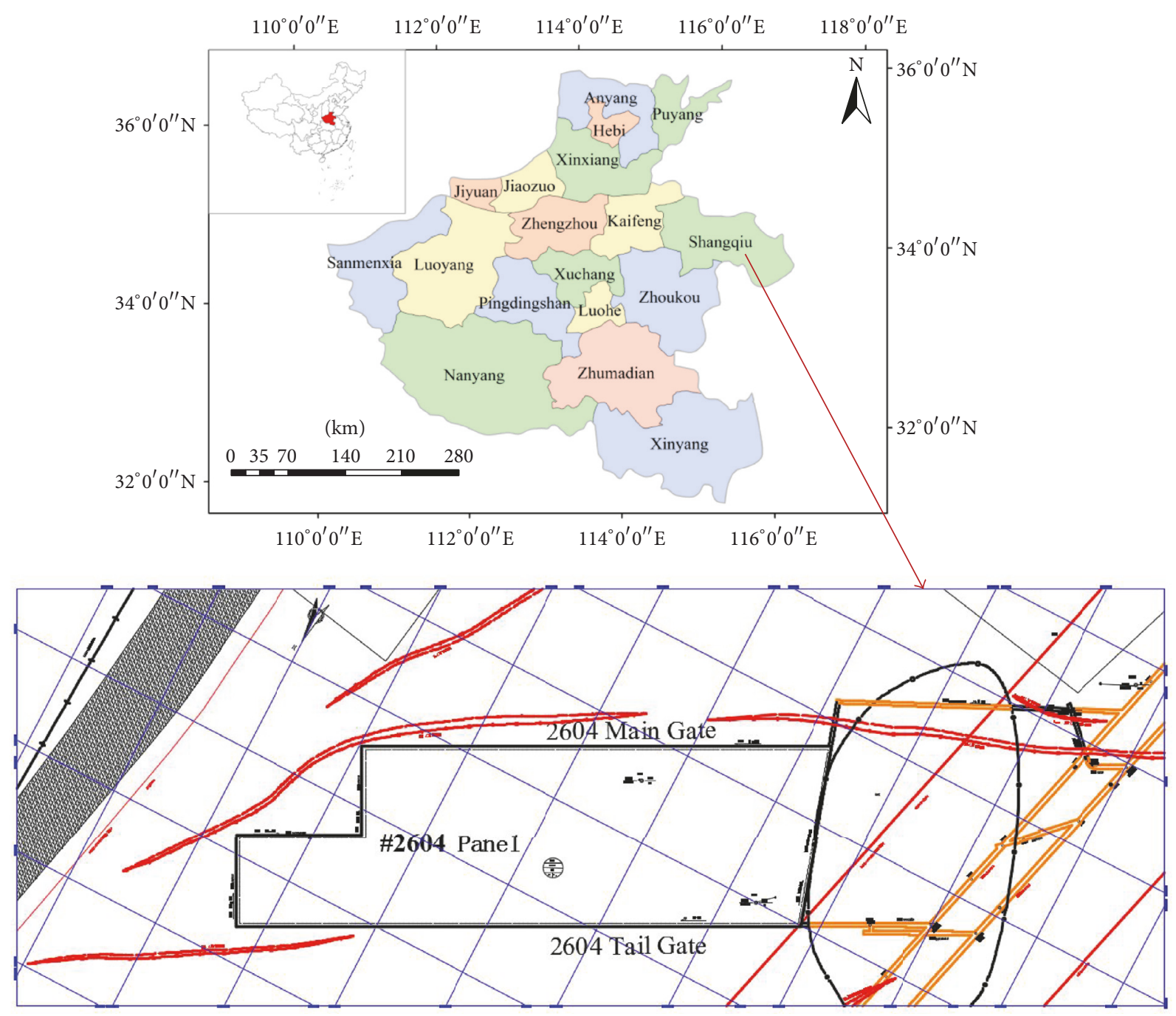

FIGURE 1: Location and layout of selected site mine.

master station, respectively. Mentioned branch station is equipped with a single component geophone, frequency selection, wireless transfer, and so on. In addition, a hardwired interface is also left at each branch station to transmit weak seismic signals to the master station. Meanwhile, 1 to $n$ network communication mode is default to guarantee the data transmitted in real-time with frequency domain. Once these data are collected and transferred to waveforms in real-time, recorded information in master station can be analysed through personal computer. The main performance parameters of this system are illustrated in Table 1.

3.2. Conversion between Energy and Level Amplitude in Seismic Signals. It is well known that the relationship between the electric level amplitude and seismic intensity in the TDS-6 microseismic monitoring system can be normalized by regression. Similarly, the relationship between seismic energy and level amplitude can be deduced on the basis of the relationship between seismic intensity and magnitude [20].
TABLE 1: Main performance parameters of TDS-6 MMS.

\begin{tabular}{lc}
\hline Parameter & Value \\
\hline Vibration band & 1.0 to $80.0 \mathrm{~Hz}$ \\
Vibration sensitivity & $20 \mathrm{~V} \cdot \mathrm{s} / \mathrm{m}$ \\
Data acquisition & $16 \mathrm{bits}, \mathrm{A} / \mathrm{D}$ converter \\
Sampling rate & $1,000 \mathrm{~s}^{-1}$ \\
Transmitted power & $1.5 \mathrm{~W}$ \\
Centre frequencies & 10,35, and $70 \mathrm{~Hz}$ \\
Carrier frequency & $450 \mathrm{MHz}$ \\
Receiving sensitivity & $0.3 \mu \mathrm{V}$ \\
Working temperature range & $-10^{\circ} \mathrm{C}$ to $50^{\circ} \mathrm{C}$ \\
\hline
\end{tabular}

As seen from Figure 6, the conversion between seismic intensity and level amplitude can be expressed as follows:

$$
y=1.4405 \ln x-1.9517
$$




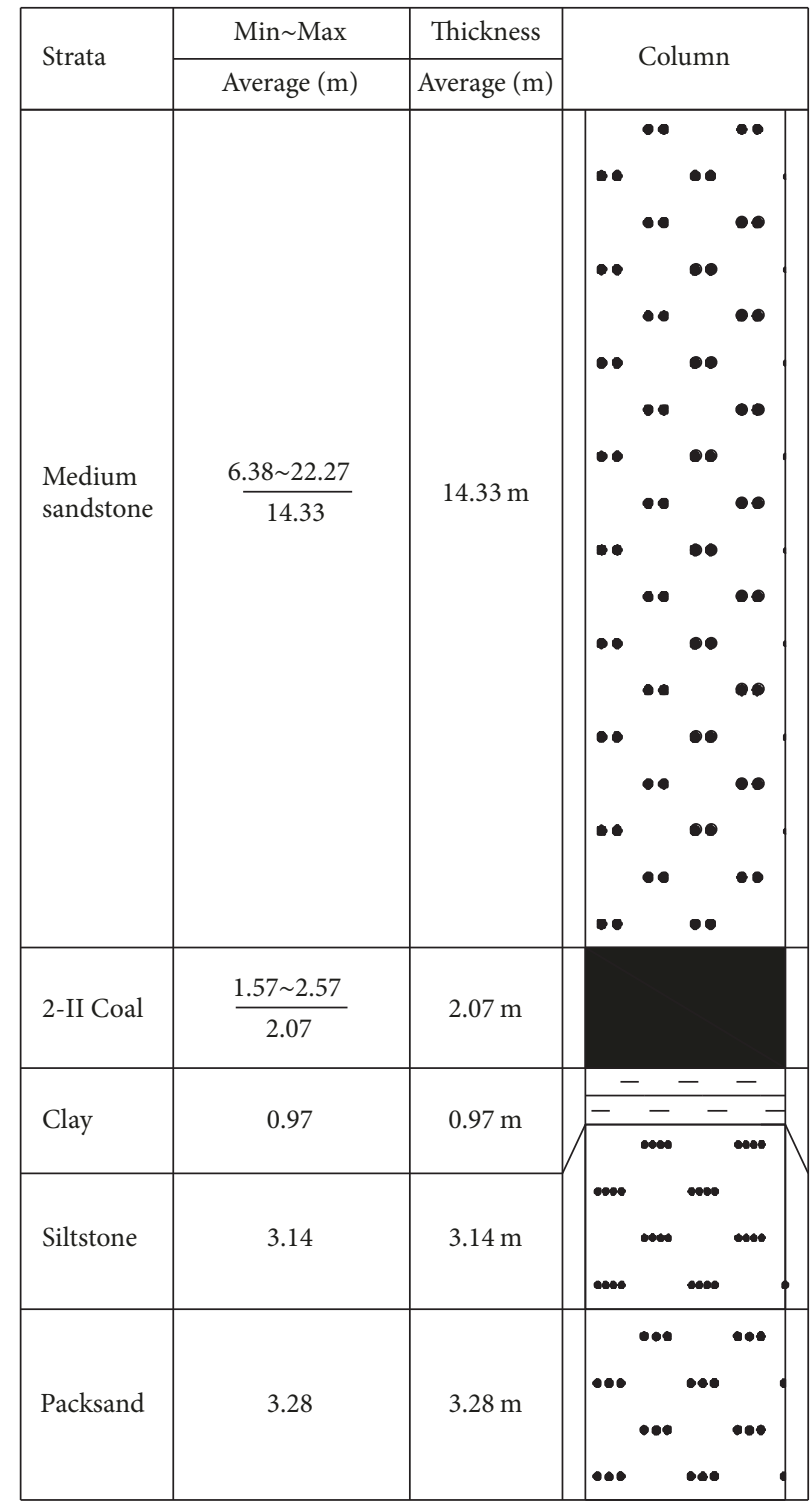

Figure 2: Combined geological column of coal seams.

As seen from Figure 7, the conversion between magnitude and seismic intensity was given by [11]

$$
y=0.5708 x+1.6556
$$

While the conversion between energy and magnitude can be expressed as (Figure 8)

$$
\begin{aligned}
y & =63207 e^{3.4538 x}, \\
\lg y & =4.8+1.5 x,
\end{aligned}
$$

therefore, the relationship between energy and level amplitude was:

$$
\lg y=5.6+1.233 \ln x \text {, }
$$

where $y$ is the seismic energy of each particle, J, and $x$ is the level amplitude of the seismic signal, $\mathrm{mV}$.

\section{Experiment Design and Instrument}

Considering that the main aims of this research are to investigate the effect of blasting vibration wave propagation and the response of blasting vibration wave at different sections of roadway, the stress at different time periods and wave propagation signal data were measured and analyzed to reveal the blasting vibration wave in the underground coal seam roadway. The propagation law, attenuation characteristics, and their relationship with the roadway surrounding rock were investigated as well. To achieve the mentioned research objectives, two field tests were designed and conducted: one is to evaluate wave propagation and the other is to assess the response characteristics of surrounding rock at different locations (e.g., roof, rib, and floor) of the same section of roadway. 


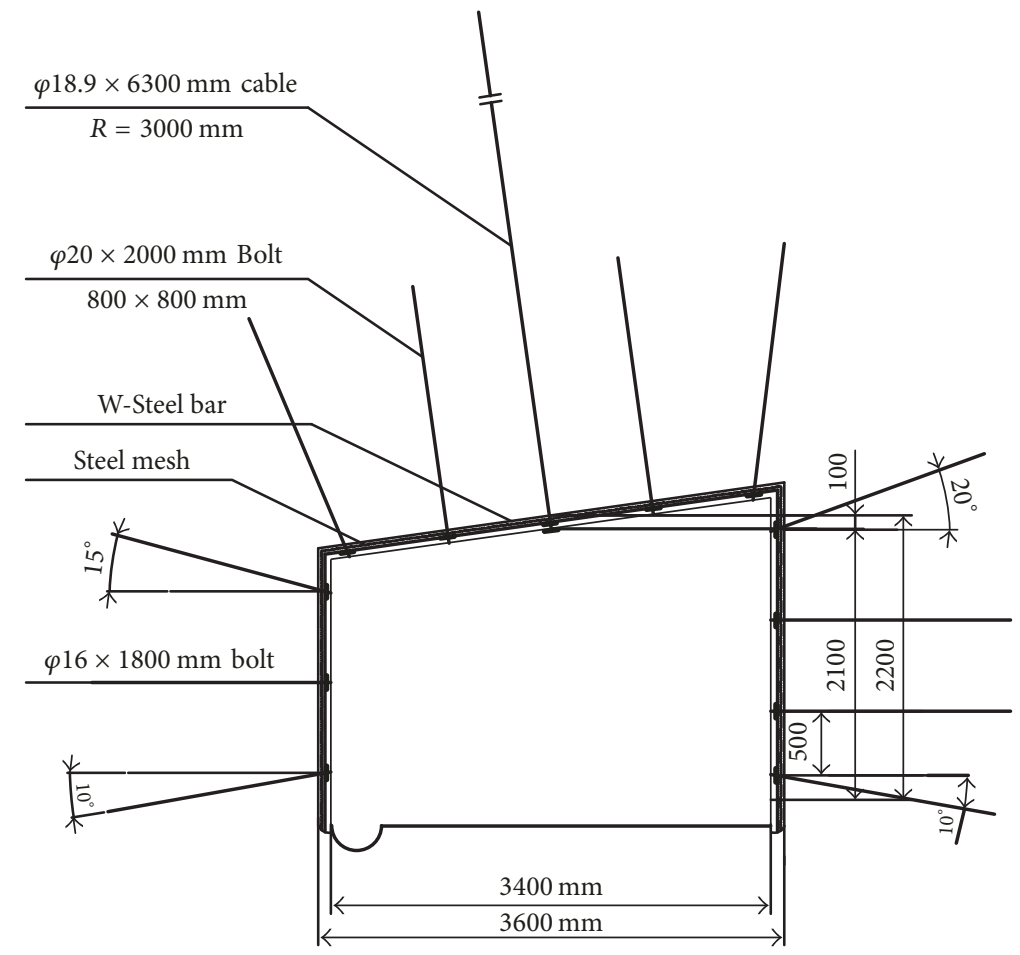

FIGURE 3: Cross section of support for tailgate.

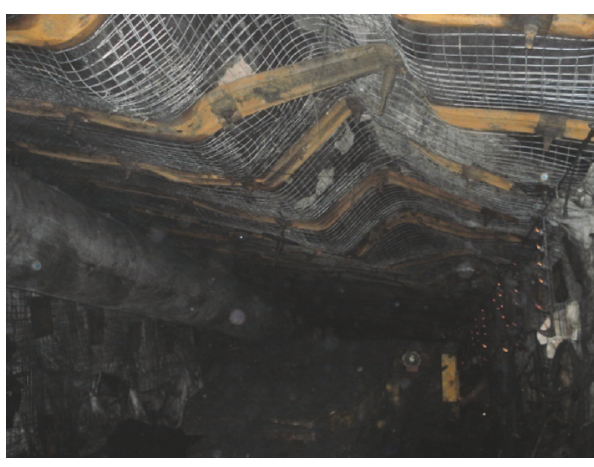

Overall seen

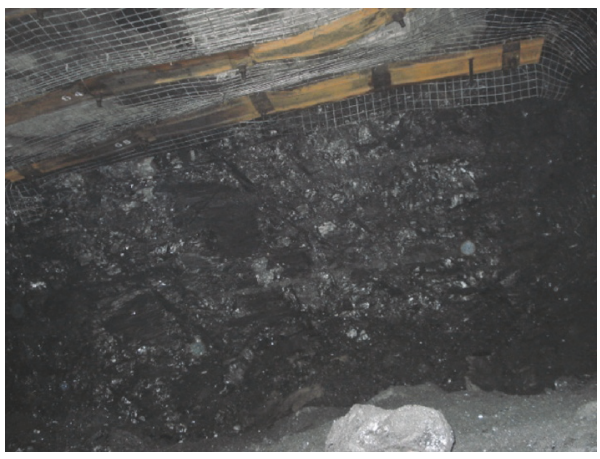

Driving ahead

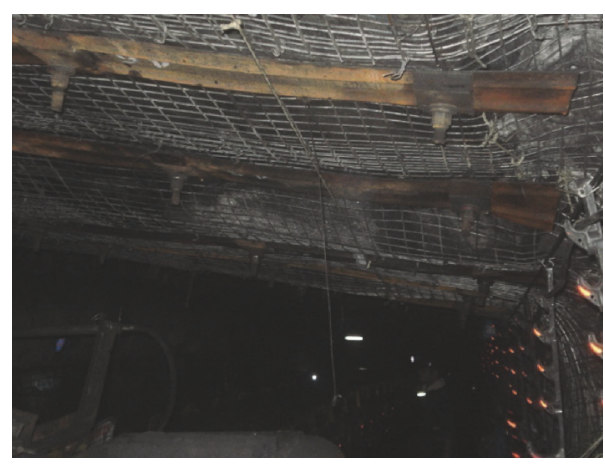

Roof

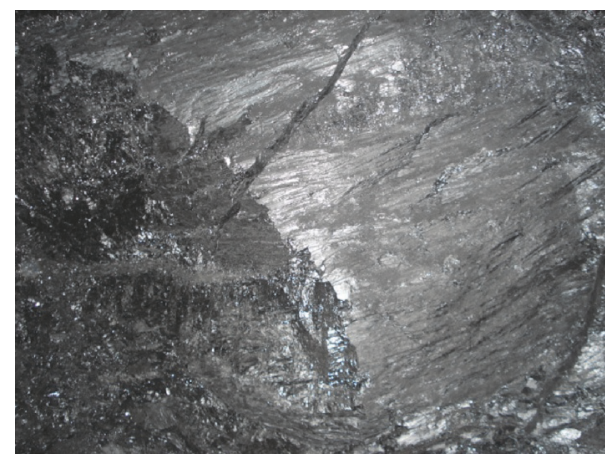

Crib

FIGURE 4: The photos of selected roadway. 


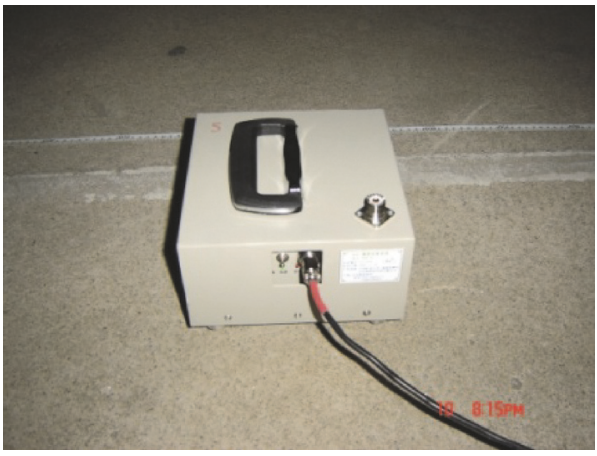

(a) Branch station

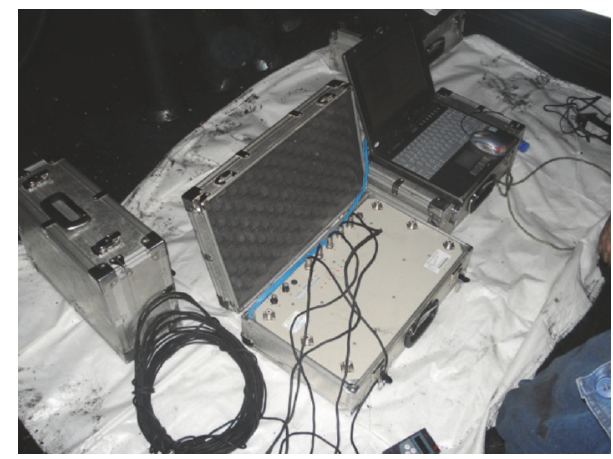

(b) Master station

FIGURE 5: TDS-6 MMS system.

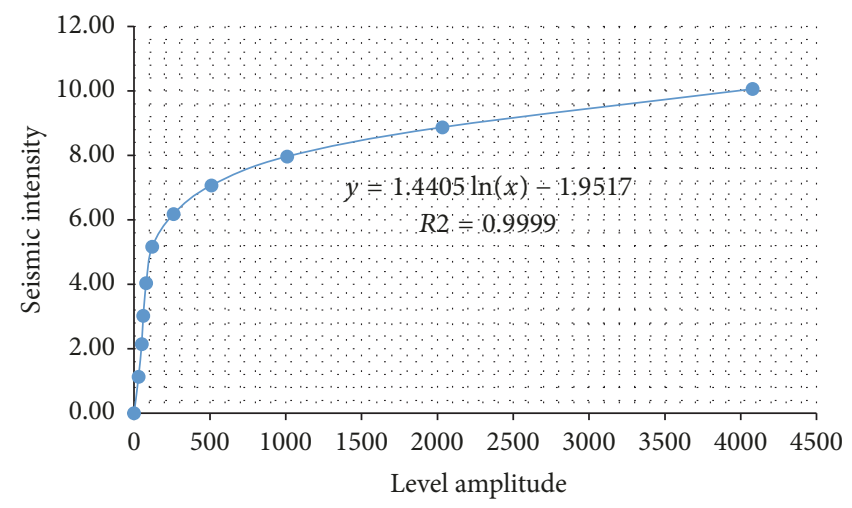

Figure 6: Intensity versus level amplitude.

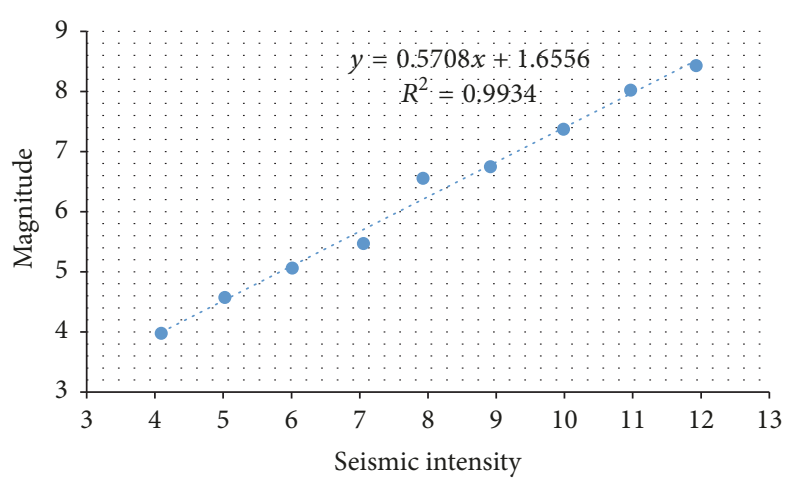

Figure 7: Magnitude versus seismic intensity.

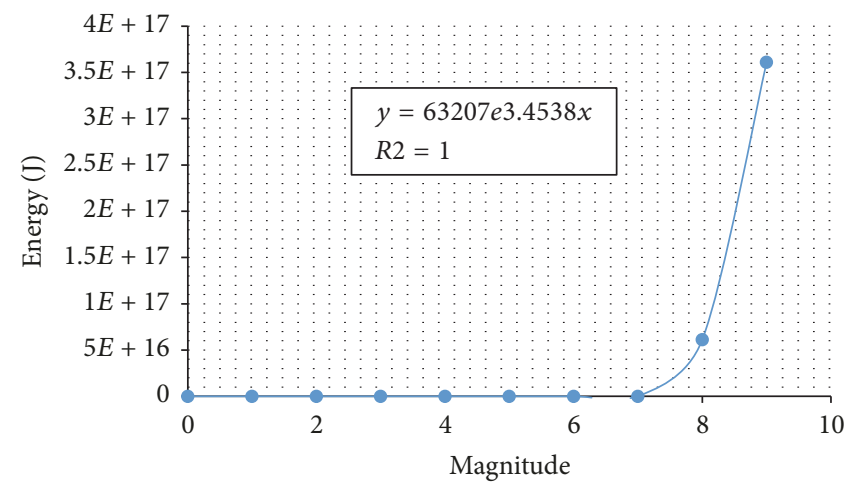

Figure 8: Energy versus magnitude. 


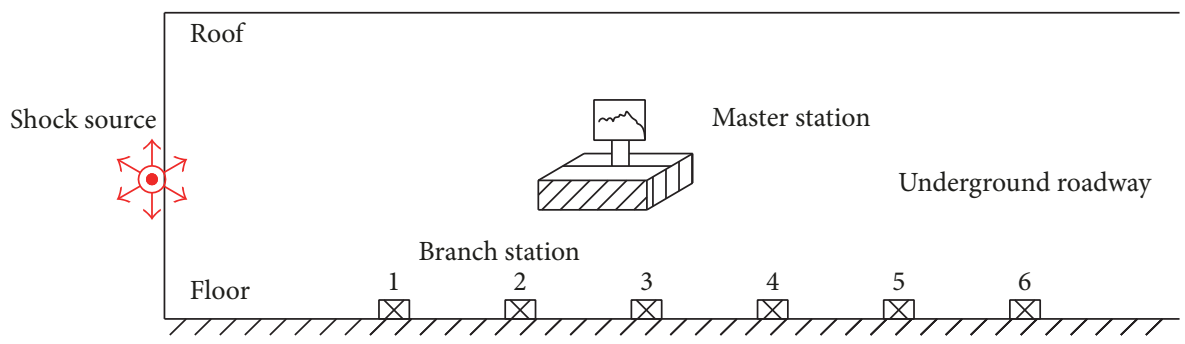

FIGURE 9: Test model of evaluation of shock wave propagation.

\subsection{Experiment Design}

4.1.1. Test 1: Propagation Effect of Vibration Wave along the Roadway. As shown in Figure 9, roadway with concrete surface located at coal seam was selected to set up MMS. A small scale of explosive was stimulated to simulate shock source in rock burst. Six branch stations were placed $10 \mathrm{~m}$ apart from the shock source along the strike direction of roadway; the master station was placed in the middle of the array of branch stations. Each test should be conducted more than three times to obtain the reliability of the test results.

4.1.2. Test 2: Response Characteristics of Surrounding Rock at Different Locations around the Same Section. Before setting up any equipment, one of the sections of the same roadway should be selected. Considering the limit of the length of signal cable is limited, the substation from the main station should not be too far. Therefore, the selected section to install branch stations is located at $20 \mathrm{~m}$ apart from the explosive source. The branch station will be fixed in whole cross section of roadway including roof, floor, and two shoulders of cribs. Similarly, all tests should be repeated more than three times. It should make sure that all branch stations receiving digital signal are placed towards the direction of the source (Figure 10).

4.2. Experimental Procedure of Test 1. As discussed earlier, the master station was placed in a safety chamber $30 \mathrm{~m}$ from the roadway heading face. Each branch station was arranged in a line along the strike direction of roadway, with an average spacing of $10 \mathrm{~m}$ between each station, with the first branch station situated $10 \mathrm{~m}$ from the explosive source. In addition, the window for receiving signals at each branch station was placed toward the explosive source. Meanwhile, some critical parameters were set up; main frequency range was between 1 and $100 \mathrm{~Hz}$ in all-pass mode; trigger threshold (i.e., STA/LTA) is 1.2 ; scanning time is $1 \mathrm{~s}$. All data was recorded continuously.

Each blast hole was drilled in the roadway heading face, with a diameter and depth of $43 \mathrm{~mm}$ and $1 \mathrm{~m}$, respectively. A positive charge structure was selected, and the explosive charge was controlled at between 70 and $80 \mathrm{mg}$ each time. The cartridge length was approximately $150 \mathrm{~mm}$, and the length in each blast hole was plugged firmly by stemming. Moreover, the blasting operation and signal monitoring were coordinated by a single person. The instrumentation arrangement and debugging procedure can be seen in Figure 11 .

4.3. Experimental Procedure of Test 2. A same cross section was selected as presented in Test 1 , different from the layout of branch station, herein, six branch stations were arranged in the middle of roof, floor, two ribs, humeral angle, and base angles of the roadway section, respectively (Figure 10). A known mass of explosives was selected as the shock source.

Master stations were placed $20 \mathrm{~m}$ from the explosive source in roadway heading face and arranged in the roof, floor, two ribs, and both humeral angles of the same roadway section, respectively. In addition, the window for receiving signal of each branch station was placed so as to face the explosive source. Meanwhile, the scanning time was set to $1 \mathrm{~s}$, and the data were recorded continuously. The blast-hole arrangement, charge structure, and amount of charge were basically the same as described in the frontal tests.

The main station was equipped with computer placed in the distance $30 \mathrm{~m}$ from the head to avoid the chamber. As the length of the test equipment signal cable is limited, the substation from the main station should not be too far, selecting the distance of $20 \mathrm{~m}$ cross-site location substation. The substation will be fixed in the roadway section of the roof, floor, two ribs, and two shoulders and shoulder position; the substation to receive the signal should be placed towards the direction of the source. After all the test equipment is finished, open the power supply of each substation and the main station and enter the main interface of the microearthquake information acquisition system; set the monitoring parameters, and 2604 track chute vibration wave propagation effect test parameters are set the same. Data recording mode uses continuous recording; continuous recording is selected to start monitoring; the program continues to record the substation to collect data in the computer hard disk; choose stop monitoring and stop recording. Before the test, all wire connectors between each equipment including substation and the main station were carefully detected to maintain the normal use in experiment. Unfortunately, all substations except for 6 substations 


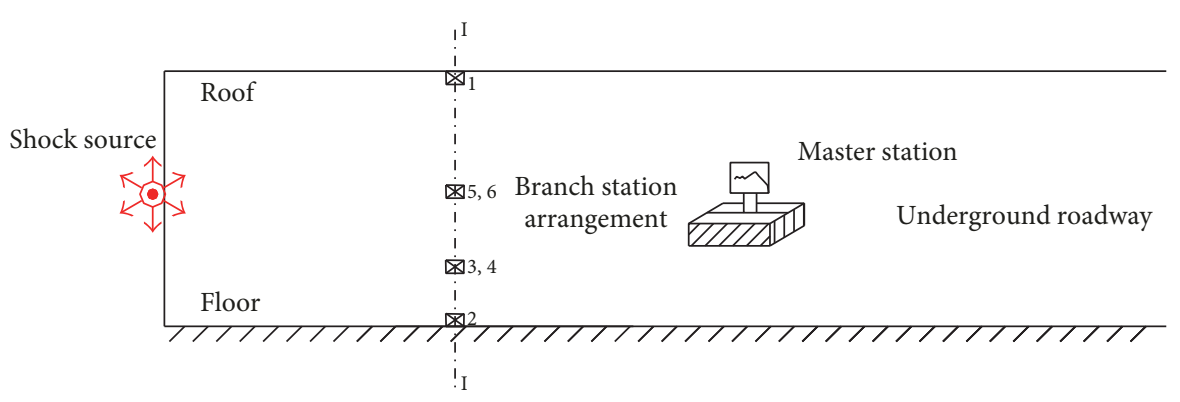

(a) Instrument arrangement

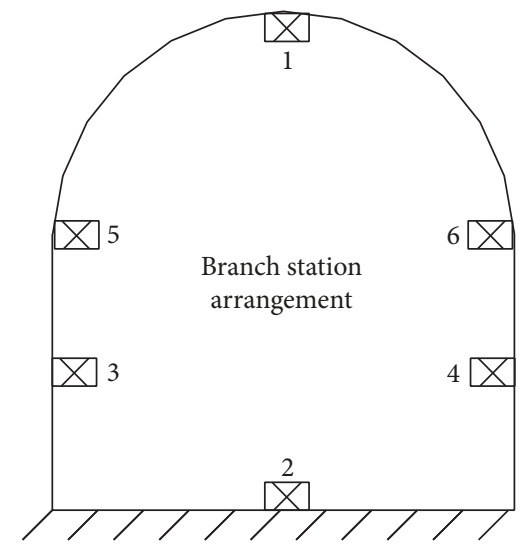

(b) Section I-I

FIGURE 10: Test model of response characteristics at different locations on the same roadway.

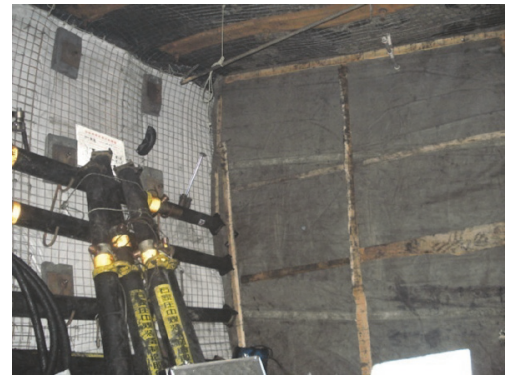

(a) Selection of location

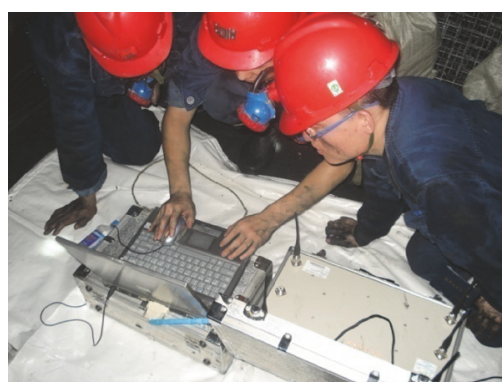

(d) Debugging system

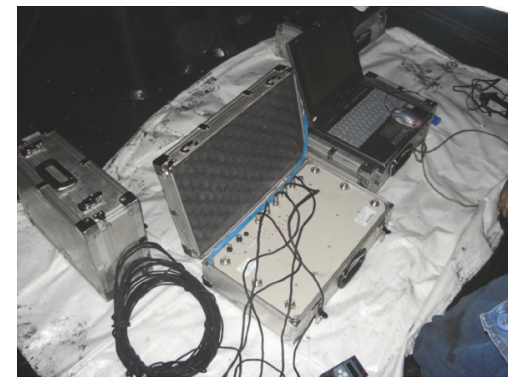

(b) Setting up master station

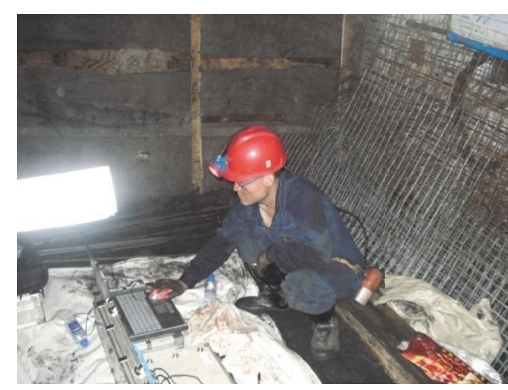

(e) Collection of data

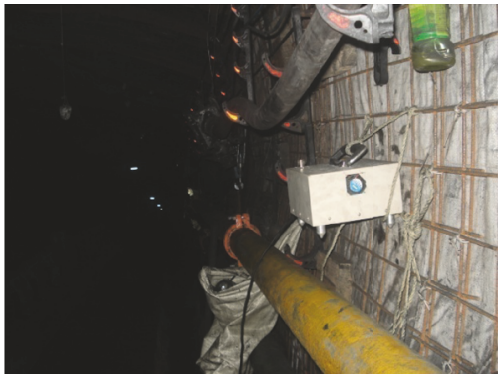

(c) Connection of branch station

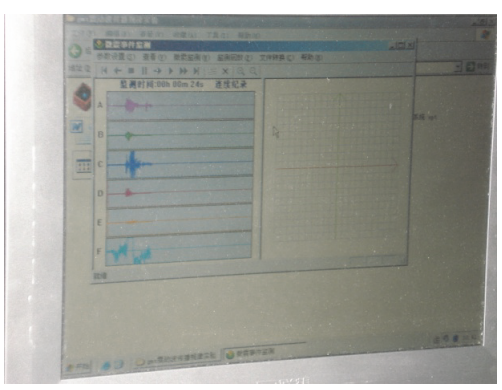

(f) Analysis data

FIGURE 11: Experimental procedure of Test 1.

did not work. That is, only five substations were used in this experiment.

\section{Experimental Observations and Discussions}

5.1. Data Collection from Two Experiments. The original voltage data recorded by the TDS- 6 was converted into an MS-Access ${ }^{\circledR}$ database file and an acceleration database file, successfully. In addition, the energy time-history curves in each branch station and from each test were then obtained and processed in MS-Excel ${ }^{\circledR}$ and MATLAB ${ }^{\mathrm{TM}}$ 7.0. Due to space limitations of article, the level amplitude and energy timehistory curves from different branch stations, in each blasting test, are provided, respectively.

The original explosive signals from microexplosions in front of the roadway heading face (from three tests) and the amplitude-time curve of the vibration signal level of each branch station of 2604 panel obtained from Test 1 can be seen in Figures 12 and 13, respectively. Correspondingly, the original signals obtained from Test 2 were presented in Figures 14 and 15, respectively. 


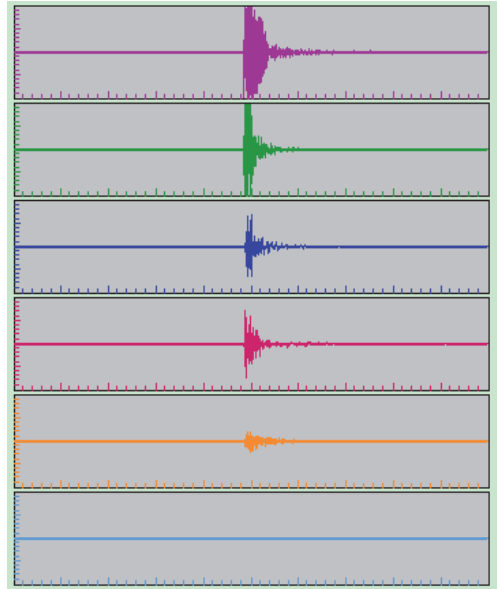

110910115940

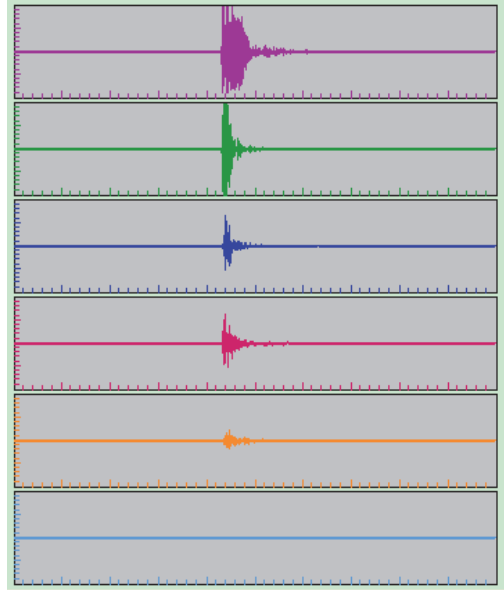

110910115940

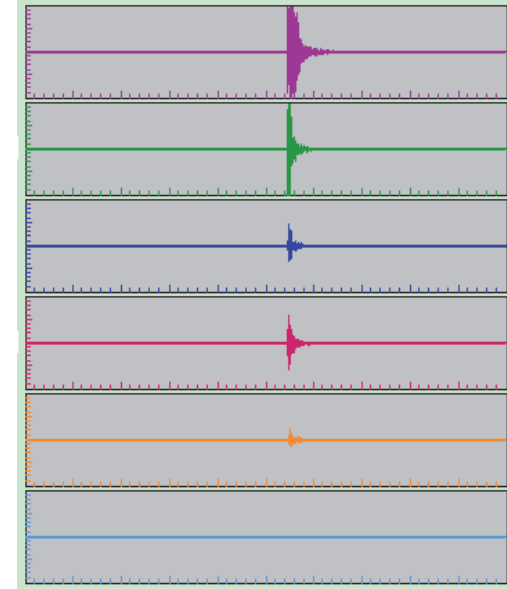

110910122035

FIGURE 12: Propagation effect of vibration wave along the roadway (original signal).

5.2. Propagation Effect of Vibration Wave along the Roadway. According to the data of the amplitude of the vibration signal in the vertical direction of each particle station, the maximum amplitude curve of each substation is obtained by data analysis, as shown in Figure 16. The vibration effect of blasting wave along the roadway is summarized from vibration signal received by each branch station. The maximum amplitude of each station is plotted after regression analysis.

The amplitude of the vibration signal level detected by each test station was found by data processing from three tests conducted at each group. The average value of the amplitude of the vibration signal level monitored by each substation was obtained. Correspondingly, the regression curves of the maximum amplitude of the vibration signal level along the roadway are obtained. The vibration signal amplitude descending curve regression equation is obtained as follows:

$$
y=15133 e^{-0.05 x} .
$$

From the amplitude curve of the vibration signal level of the coal roadway and the regression equation, it can be seen that the amplitude of the distance from the source is large, but the amplitude of the vibration signal increases along the propagation distance in the exponential relationship attenuation.

\subsection{Energy Response Characteristics of Blasting Vibration} Wave in Surrounding Rock with Same Location. The energy dissipation of the blasting vibration wave in the surrounding rock of the coal roadway is revealed by the energy propagation effect of the blasting vibration wave in the surrounding rock of the coal roadway. The results of the energy calculation of the blasting vibration wave at the substation position of the 2604 orbit test site are shown in Table 2.
By nonlinear regression, the energy attenuation of the explosive wave transmitted through the coal-rock mass was obtained as follows:

$$
y=1 \times 10^{9} e^{-0.154 x} .
$$

Herein, $y$ is the seismic energy, $\mathrm{J}$, and $x$ is the distance to the seismic source, $\mathrm{m}$.

From the curves of peak amplitude and energy attenuation, the shock wave attenuated exponentially as $E=$ $E_{0} e^{-\eta l}$ with distance from the seismic source: the amplitude decreased significantly after $20 \mathrm{~m}$, and the signal was very weak beyond $30 \mathrm{~m}$ as shown in Figure 17.

5.4. Energy Response Characteristics of Blasting Vibration Wave of Surrounding Rock in Different Locations. Calculated peak amplitudes and seismic energies received at different branch stations in each test are listed in Table 3.

The response characteristics of the underground engineering structure to the blast shock wave and the difference of the response of the different location to the blasting vibration wave are studied through the alteration of the energy response characteristics of the blasting vibration wave at different sections of the same roadway. To reduce the impact of vibration damage intensity of the technical approach, the results of the energy calculation of the blasting vibration wave at the substation position of the 2604 orbit test site are shown in Table 3.

It is apparent that he response mechanics are characteristic with the real location of surrounding rock despite being at the same section. Compared with the surrounding rock, the floor is under much damage, followed by the ribs, the roof, and the humeral angles (Figure 18). 
TABLE 2: Calculated peak amplitudes and energies at each branch station.

\begin{tabular}{lccccccc}
\hline \multirow{2}{*}{ Test site } & \multirow{2}{*}{ Branch station } & \multirow{2}{*}{ Distance to source/m } & \multicolumn{3}{c}{ Peak amplitudes at each branch station/ $\mu \mathrm{V}$} \\
& & & Test 1 & Test 2 & Test 3 & Average value \\
\hline & 1 & 10 & 7388.867 & 10680.9 & 9623.4 & 9231.056 & $2.19 \times 10^{8}$ \\
& 2 & 20 & 6971.067 & 6416.8 & 6991 & 6792.956 & $9.065 \times 10^{7}$ \\
Roadway: 2604 panel & 3 & 30 & 2581.133 & 2915.1 & 2945.6 & 2813.944 & $7.508 \times 10^{6}$ \\
& 4 & 40 & 2375.733 & 2808.1 & 2235.5 & 2473.111 & $5.203 \times 10^{6}$ \\
& 5 & 50 & 984.4667 & 1065.3 & 986.3 & 1012.022 & $4.11 \times 10^{5}$ \\
\hline
\end{tabular}
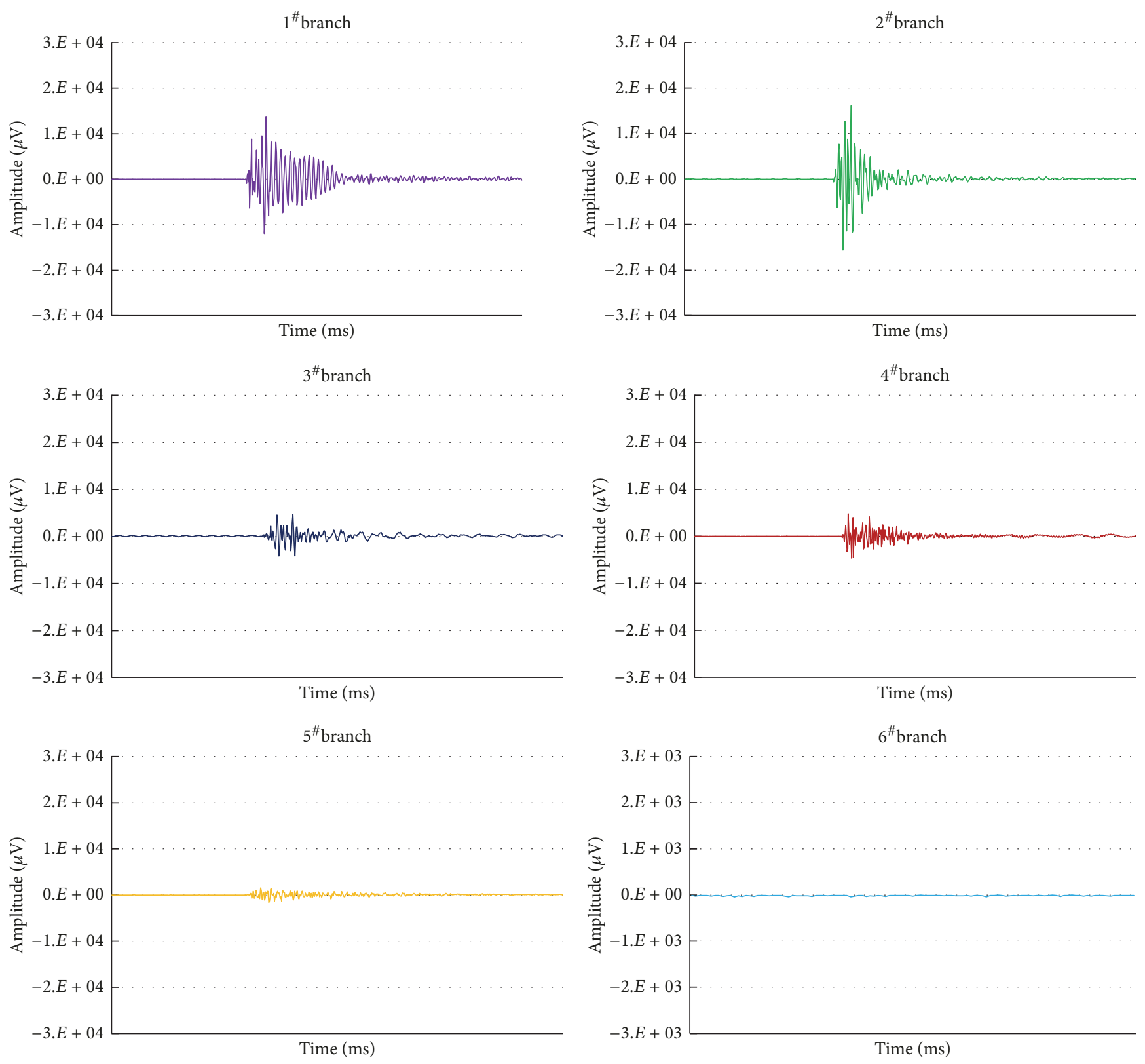

FIGURE 13: The amplitude-time curve of the vibration signal level of each branch station of 2604 panel. 
TABLE 3: Calculated peak amplitudes and seismic energies received at each branch station.

\begin{tabular}{|c|c|c|c|c|c|c|c|}
\hline \multirow{2}{*}{ Test site } & \multirow{2}{*}{ Branch station } & \multirow{2}{*}{ Location } & \multicolumn{4}{|c|}{ Maximal amplitudes of each branch station $/ \mu \mathrm{V}$} & \multirow{2}{*}{ Energy/J } \\
\hline & & & Test 1 & Test 2 & Test 3 & Average value & \\
\hline \multirow{5}{*}{ Roadway of 2604 coal face } & 1 & Floor & 4969.545 & 5527.364 & 4918.6 & 5138.503 & $4.15 \times 10^{7}$ \\
\hline & 2 & Roof & 949.0909 & 2079.545 & 1228.8 & 1419.145 & $1.076 \times 10^{6}$ \\
\hline & 3 & Left rib & 3276.091 & 3414.909 & 2922.2 & 3204.4 & $1.086 \times 10^{7}$ \\
\hline & 4 & Humeral angle & 2040.364 & 2036.182 & 1792.2 & 1956.248 & $2.675 \times 10^{6}$ \\
\hline & 5 & Right rib & 3575.636 & 4917.818 & 2922 & 3805.152 & $1.77 \times 10^{7}$ \\
\hline
\end{tabular}

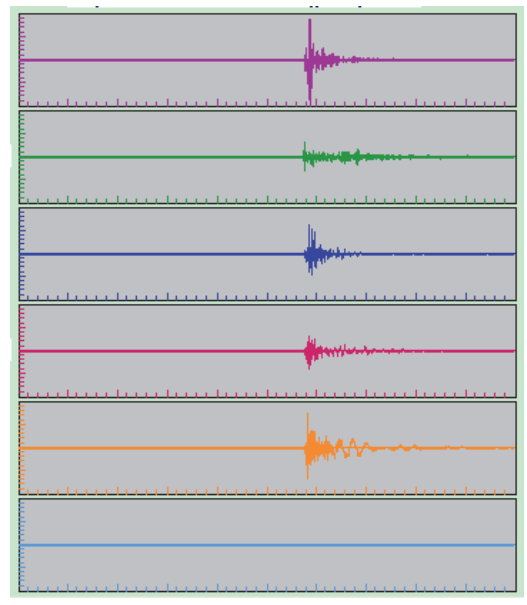

110910132836

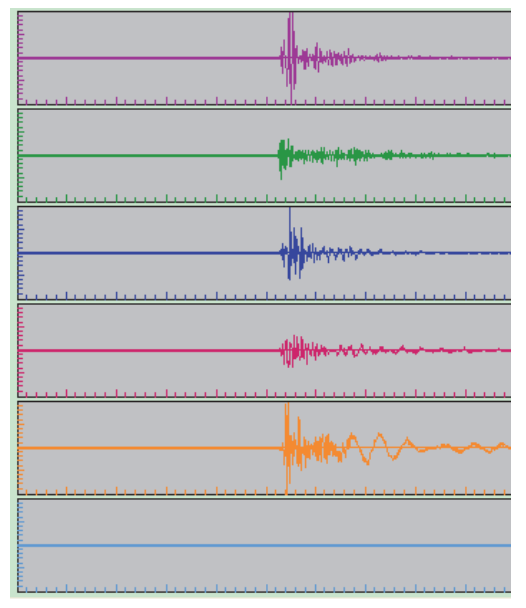

110910131838

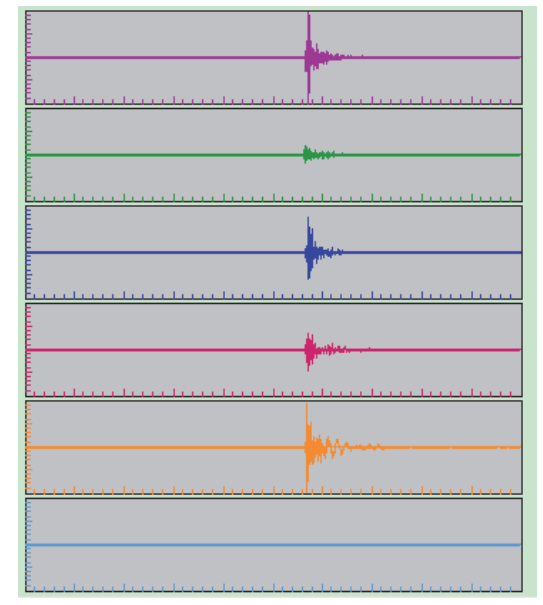

110910130719

FIGURE 14: Response characteristics of surrounding rock at different locations around the same section (original signal).

\section{Conclusions}

This paper presents a first ever in situ experimental approach to investigate the behavior of rock burst in coal mine roadway. TDS-6 microseismic monitoring system was applied to evaluate shock wave propagation effects caused by microexplosions in a roadway and the response characteristic evaluation of the rocks surrounding the roadway at different locations around the same section, respectively. In addition, the relationship between the vibration and the damage effect was successfully explored. In summary, the following conclusions can be drawn from this in situ research:

(1) The seismic energy of a shock wave in a coalrock mass attenuates exponentially as $E=E_{0} e^{-\eta l}$ with increasing distance from the explosive source. However, the amplitude decreases significantly after $20 \mathrm{~m}$ and becomes very weak after $30 \mathrm{~m}$. It is believed that the effect of vibration caused by blasting is limited owing to the decrease of energy observed by surrounding rock.

(2) The response characteristics of the rocks surrounding the roadway differ significantly at different locations around the same section; that is, the floor suffered the most serious damage, followed by the two ribs, the roof, and the humeral angles: this is consistent with actual situations in which the floor always suffers the most serious damage after a rock burst.

(3) Compared to traditional experimental approaches which are either conducted in laboratory or on the surface to simulate the occurrence of rock burst, the new in situ experimental method presented in this paper is much more direct and reasonable with its reliable results.

It should be noted that the propagation effect of shock wave mainly depends on different rock surroundings with different mechanical properties, the fillings, water saturation, and so on under particular geological condition. Even though this paper presented a novel effective method to evaluate rock burst by in situ experimental approach, much investigation should be conducted to deepen the understanding of behavior of rock burst in prevention design. 

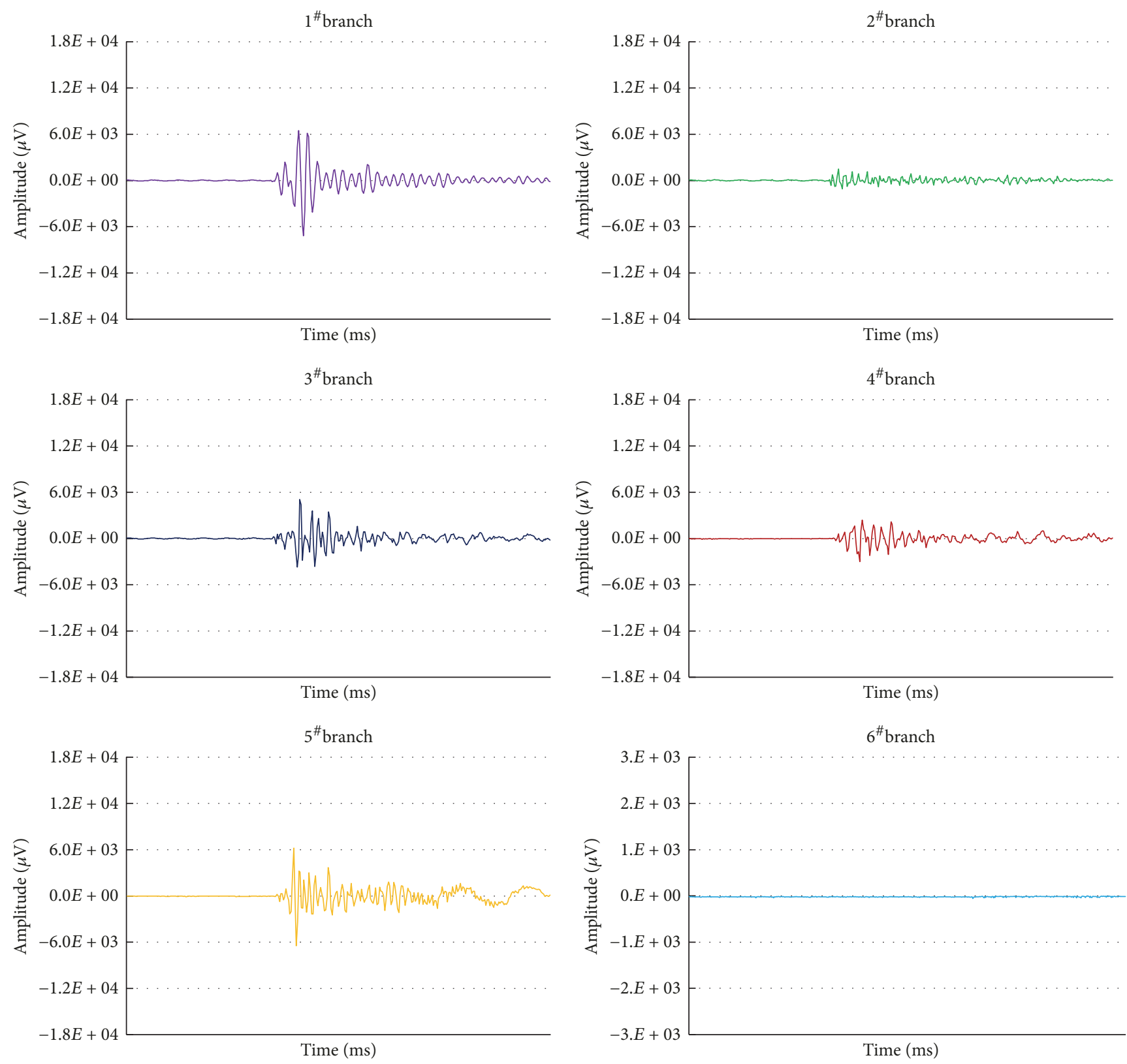

FIGURE 15: Level amplitude-time curves from different branch stations: different locations in the same section.

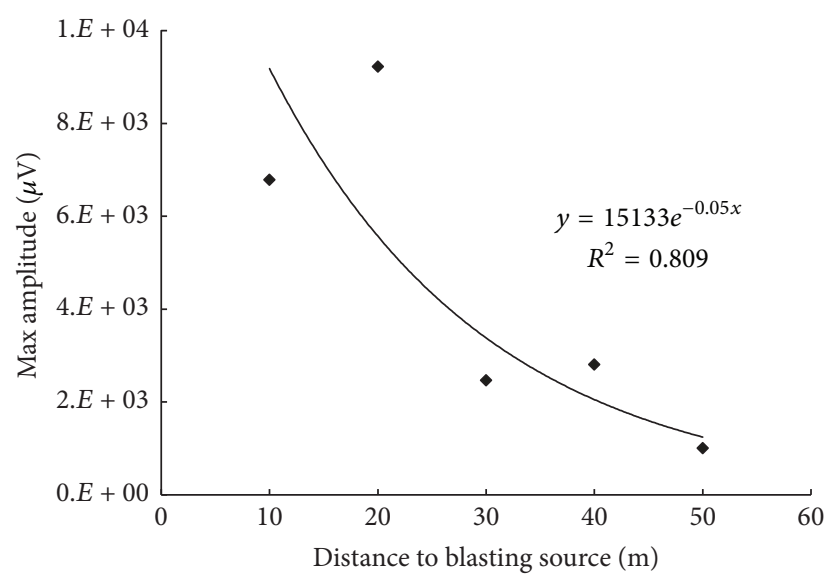

FIGURE 16: Relationship between vibration signal level amplitude and distance to blasting source. 


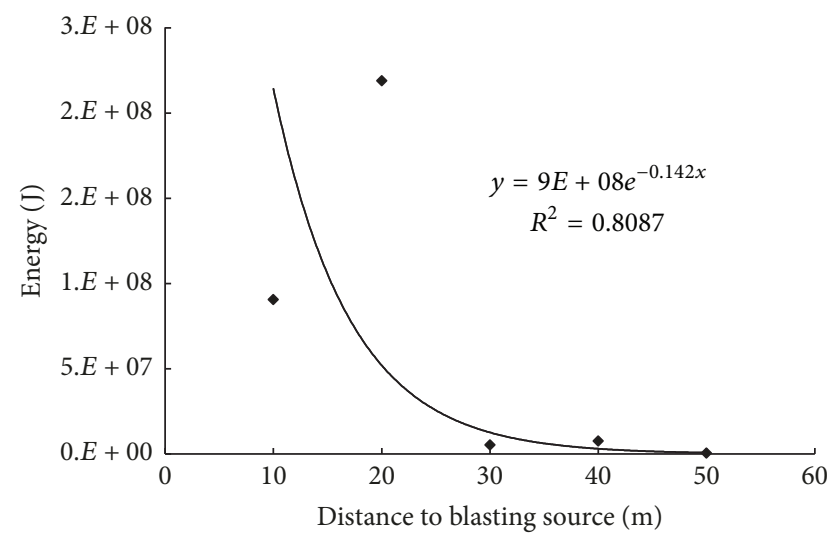

FIGURE 17: Relationship between energy and distance to blasting source.

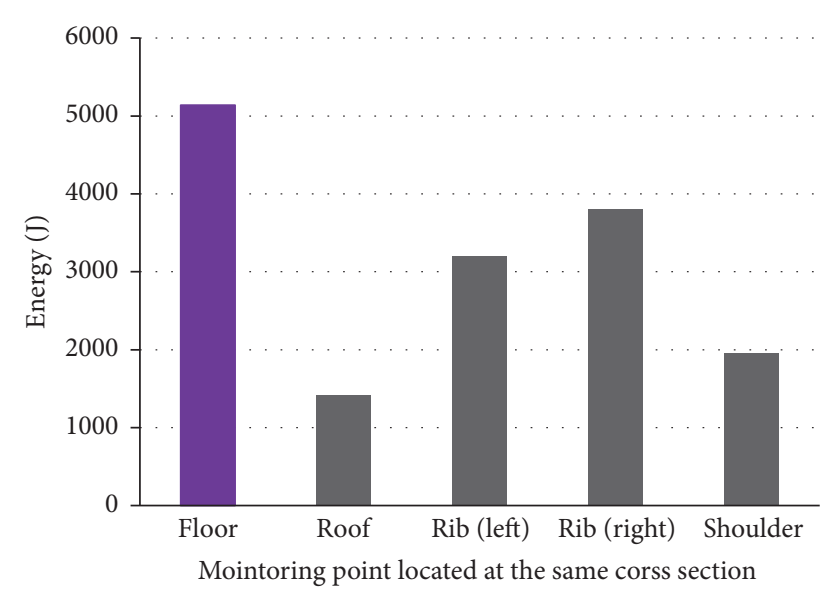

FIGURE 18: The distribution of obtained energy at different locations.

\section{Conflicts of Interest}

The authors declare no conflicts of interest.

\section{Acknowledgments}

The authors would like to acknowledge the financial supports provided by National Natural Science Foundation Project of China (51564044), Tian-Shan Scholars Project (TSS20150105), and Qing-lan Talents Cultivation Project (JSQL20140207).

\section{References}

[1] M.-C. He, J.-L. Miao, and J.-L. Feng, "Rock burst process of limestone and its acoustic emission characteristics under truetriaxial unloading conditions," International Journal of Rock Mechanics and Mining Sciences, vol. 47, no. 2, pp. 286-298, 2010.

[2] H. P. Xie, J. F. Liu, Y. Ju, J. Li, and L. Z. Xie, "Fractal property of spatial distribution of acoustic emissions during the failure process of bedded rock salt," International Journal of Rock Mechanics and Mining Sciences, vol. 48, no. 8, pp. 1344-1351, 2011.
[3] L. Dou, X. He, E. Wang, and D. Gu, "Electromagnetic emissions in rock and coal burst failures," Journal of Tsinghua University, vol. 41, no. 12, pp. 86-88, 2001.

[4] C. Wang, A. Cao, G. Zhu, G. Jing, J. Li, and T. Chen, "Mechanism of rock burst induced by fault slip in an island coal panel and hazard assessment using seismic tomography: a case study from Xuzhuang colliery, Xuzhou, China," Geosciences Journal, vol. 21, no. 3, pp. 469-481, 2017.

[5] C. Zhang, I. Canbulat, B. Hebblewhite, and C. R. Ward, "Assessing coal burst phenomena in mining and insights into directions for future research," International Journal of Coal Geology, vol. 179, pp. 28-44, 2017.

[6] G.-A. Zhu, L.-M. Dou, W. Cai et al., "Case study of passive seismic velocity tomography in rock burst hazard assessment during underground coal entry excavation," Rock Mechanics and Rock Engineering, vol. 49, no. 12, pp. 4945-4955, 2016.

[7] J.-C. Wang, F.-X. Jiang, X.-J. Meng, X.-Y. Wang, S.-T. Zhu, and Y. Feng, "Mechanism of rock burst occurrence in specially thick coal seam with rock parting," Rock Mechanics and Rock Engineering, vol. 49, no. 5, pp. 1953-1965, 2016.

[8] Y. Cheng, J. Bai, Y. Ma, J. Sun, Y. Liang, and F. Jiang, "Control mechanism of rock burst in the floor of roadway driven along next goaf in thick coal seam with large obliquity angle in deep well," Shock and Vibration, vol. 2015, Article ID 750807, 10 pages, 2015.

[9] M. Gao, "Prevention mechanism of roadway supported by boltmesh subjected to rock burst and degree calculation," Journal of Mining \& Safety Engineering, vol. 26, no. 4, pp. 402-406, 2009.

[10] J. Wang, J. Ning, J. Jiang, T. Bu, and X. Shi, "Research on the energy criterion for rockbursts induced by broken hard and thick rock strata and its application," Geotechnical and Geological Engineering, vol. 35, no. 2, pp. 731-746, 2017.

[11] L.-M. Dou, Z.-L. Mu, Z.-L. Li, A.-Y. Cao, and S.-Y. Gong, "Research progress of monitoring, forecasting, and prevention of rockburst in underground coal mining in China," International Journal of Coal Science \& Technology, vol. 1, no. 3, pp. 278288, 2014.

[12] C. Wu, R. Jia, and T. Qiu, "Rock burst monitoring and early warning based on incremental learning method with SVM," Research Journal of Information Technology, vol. 5, no. 4, pp. 121124, 2013

[13] J. Wang and J. Zhang, "Preliminary engineering application of microseismic monitoring technique to rockburst prediction in tunneling of Jinping II project," Journal of Rock Mechanics and Geotechnical Engineering, vol. 2, no. 3, pp. 193-208, 2010.

[14] L.-m. Dou, X. He, and E. Wang, "Electromagnetic emission technique of monitoring rock burst and its application," Journal of China Coal Society, vol. 4, p. 004, 2004.

[15] B. Chen et al., "Real-time microseismic monitoring and its characteristic analysis during TBM tunneling in deep-buried tunnel," Chinese Journal of Rock Mechanics and Engineering, vol. 30, no. 2, pp. 275-283, 2011.

[16] N. Baisheng et al., "Forecasting rockburst with the electromagnetic emission method in coal mine," Journal-Taiyuan University of Technology, vol. 31, no. 6, pp. 609-611, 2000.

[17] M.-S. Gao et al., "Strong-soft-strong mechanical model for controlling roadway surrounding rock subjected to rock burst and its application," Rock and Soil Mechanics-Wuhan, vol. 29, no. 2, pp. 359-364, 2008.

[18] C.-P. Lu et al., "Case study of blast-induced shock wave propagation in coal and rock," International Journal of Rock 
Mechanics and Mining Sciences, vol. 47, no. 6, pp. 1046-1054, 2010.

[19] L.-m. Dou and X.-q. He, "Model for rock burst failure and its critical values of acoustic and electromagnetic emission," Journal-China University of Mining and Technology-Chinese Edition, vol. 33, no. 5, pp. 504-508, 2004.

[20] M.-S. Gao et al., "Experimental study on earthquake tremor for transmitting law of rockburst in geomaterials," Chinese Journal of Rock Mechanics and Engineering, vol. 26, no. 7, pp. 1365-1371, 2007.

[21] M.-s. Gao et al., "Cusp catastrophic model for instability of coal pillar burst damage and analysis of its application," JournalChina University of Mining and Technology-Chinese Edition, vol. 34, no. 4, p. 433, 2005. 


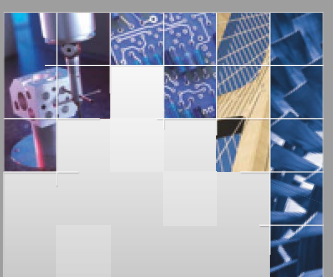

\section{Enfincering}
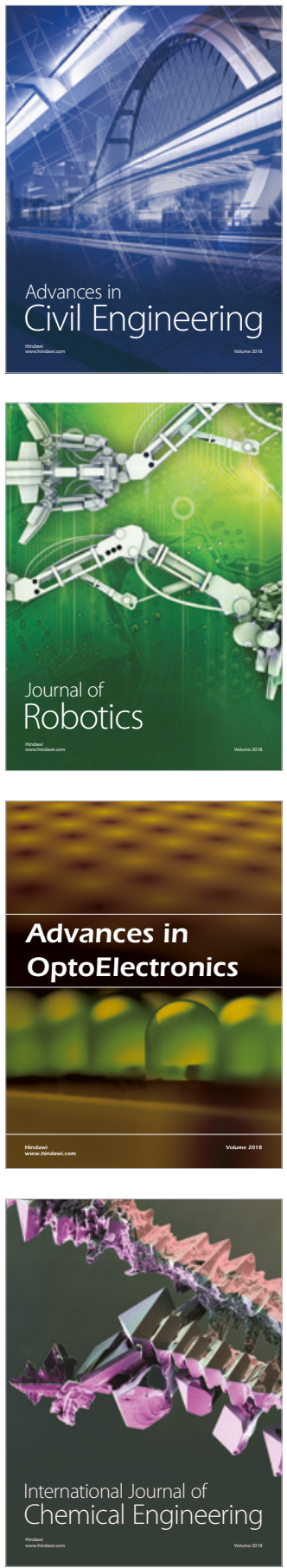

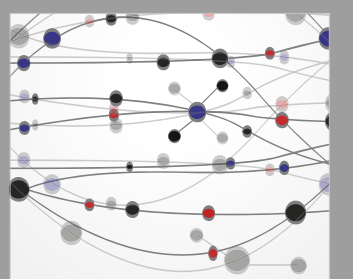

\section{Rotating \\ Machinery}

The Scientific World Journal

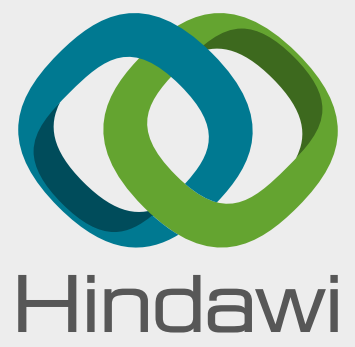

Submit your manuscripts at

www.hindawi.com
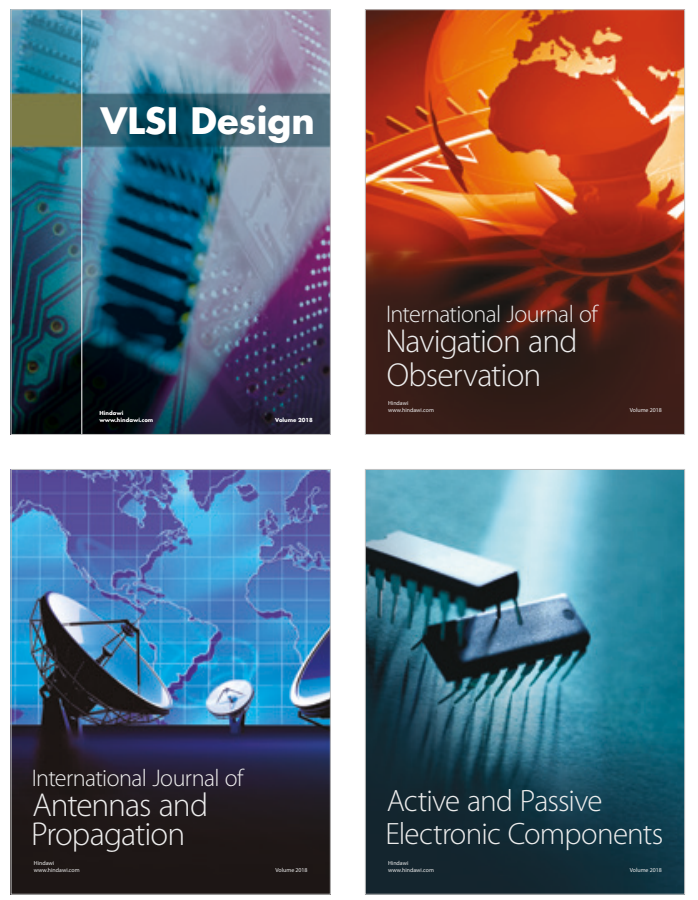
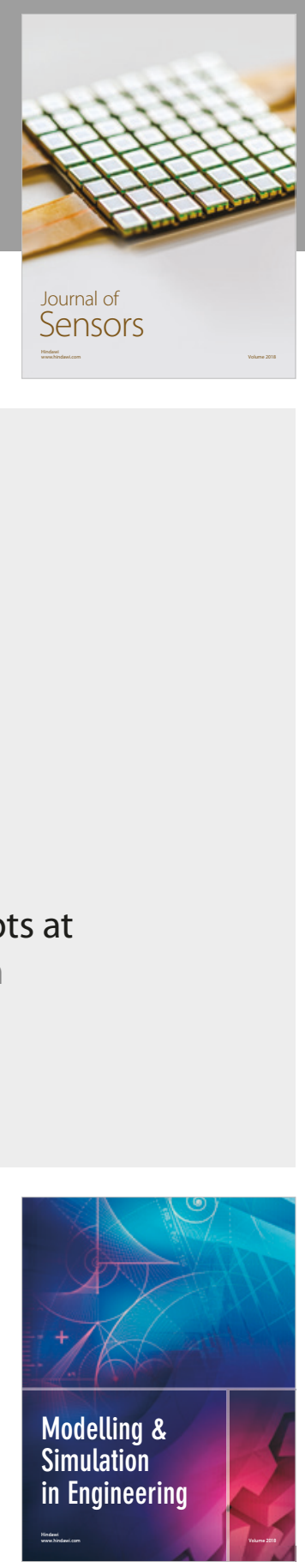

\section{Advances \\ Multimedia}
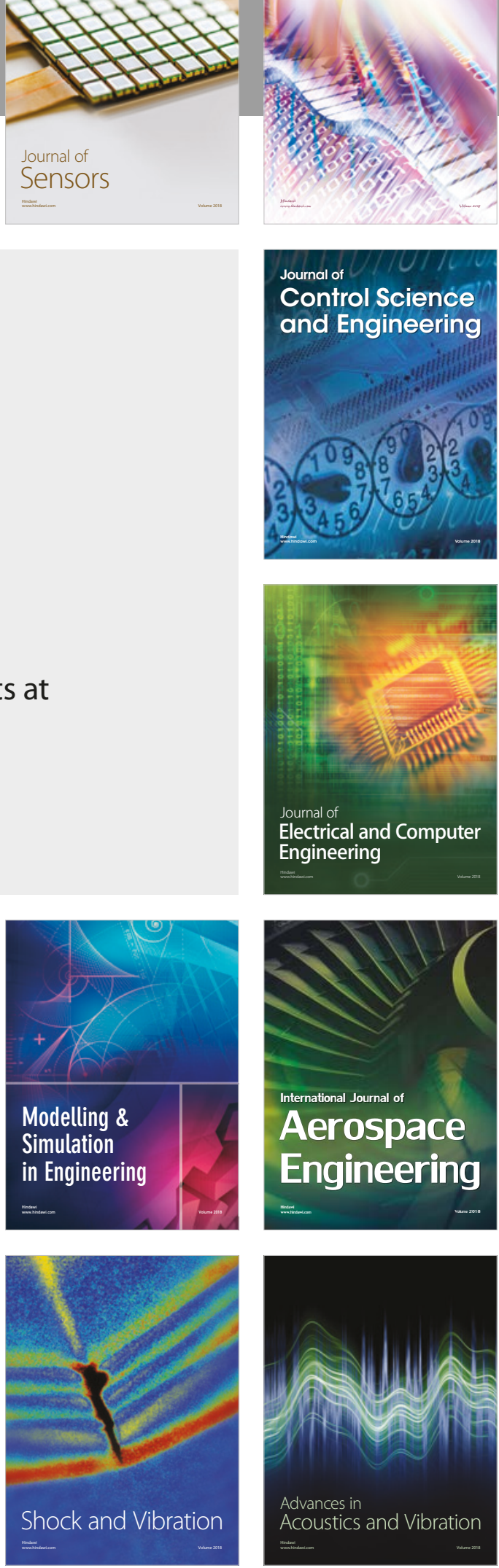